\title{
REFLEXÕES SOBRE A RELAÇÃO ESTUDANTE-UNIVERSIDADE A PARTIR DE UMA EXPERIÊNCIA DE ATENDIMENTO EM ORIENTAÇÃO PROFISSIONAL
}

\author{
Milena Mayuri Pellegrino Ogushi \\ Universidade Federal de Santa Catarina \\ milenaogushi@gmail.com \\ Marucia Patta Bardagi \\ Universidade Federal de Santa Catarina \\ marucia.bardagi@gmail.com
}

\begin{abstract}
Resumo
O período universitário expõe os estudantes a experiências que os obrigam a atualizar seus sentimentos em relação à escolha. Este artigo discute a experiência universitária a partir de uma intervenção em aconselhamento de carreira no SAPSI/UFSC, baseado no caso de uma participante. Após contextualização da Orientação Profissional e da abordagem que norteou o trabalho, é feita a descrição do grupo e, mais especificamente, do caso. Discute-se, por fim, sobre a experiência universitária no meio do curso e a importância de serviços institucionais que atendam aos anseios e questionamentos estudantis que marcam esse período. Especificamente, percebe-se o papel dos professores como modelos profissionais e fontes de informação, a necessidade de refletir junto aos alunos acerca das diferentes possibilidades de uma mesma carreira, para além do que é possível conhecer na universidade e o efeito benéfico das trocas entre os participantes do grupo durante o processo de orientação.
\end{abstract}

Palavras-chave: estudante universitário; evasão; aconselhamento de carreira.

\section{REFLECTIONS ABOUT THE STUDENT-UNIVERSITY RELATIONSHIP THROUGH AN INTERNSHIP EXPERIENCE IN CAREER COUNSELING}

\begin{abstract}
University period exposes students to experiences that require them to update their feelings about the chosen career. Based on an intervention in career counseling with university students, this article discusses the university experience through the analysis of one group member. After a description of career counseling process and of the developmental approach, the article describes the group process and more specifically the case. It is argued about the university experience in the middle of the course and the importance of institucional services that meet the wishes and student questions that mark this period. Specifically, it is clear the role of teachers as professional models and sources of information; the need to reflect with the students about the different possibilities of a career, beyond what is seen at the university and the beneficial effect of sharing between group members during the orientation process.
\end{abstract}

Keywords: university student; dropout; career counseling.

\section{REFLEXIONES SOBRE LA RELACIÓN ESTUDIANTE-UNIVERSIDAD A PARTIR DE UNA EXPERIENCIA AL CLIENTE EN ORIENTACIÓN PROFESIONAL}

\section{Resumen}

El período de la universidad expone a los estudiantes a experiencias que les obligan a actualizar sus sentimientos acerca de la elección. Este artículo aborda la experiencia universitaria de una intervención en orientación profesional en SAPsi / UFSC, basado en el caso de una participante. Después de la contextualización de Orientación Profesional y el enfoque que guió el trabajo, la descripción del grupo se hace y, más concretamente, el caso. Se sostiene, por último, sobre la experiencia universitaria en el medio del curso y la importancia de los servicios institucionales que cumplen los deseos y preguntas de los estudiantes que marcan este período. En concreto, se percibe el papel de los profesores como modelos profesionales y fuentes de información, la necesidad de reflexionar con los alumnos sobre las diferentes posibilidades de la misma carrera, más allá de lo que es posible conocer en la universidad y el efecto beneficioso sobre el intercambio entre los participantes del grupo durante el proceso de orientación.

Palavras clave: estudiante universitario; evasión; orientación profesional. 


\section{INTRODUÇÃO}

A vivência universitária é um período de constante reatualização do posicionamento do estudante frente ao seu processo de escolha. A própria trajetória de formação na universidade propicia diferentes experiências ao aluno, que o levam a confrontar-se com a realidade da profissão e à confirmação (ou não) da escolha feita (SILVA, COELHO \& TEIXEIRA, 2013). Schleich, Polydoro e Santos (2006) apontam para características cada vez mais heterogêneas que compõem o público universitário, como objetivos, expectativas, classe social, faixa etária, trajetória acadêmica anterior, dentre outras. Abarcar a necessidade dos alunos, continuam as autoras, reorganizando as instituições para melhor atendê-los por meio de programas e serviços adequados, pode auxiliar no aumento da eficácia do processo educacional e, concomitantemente, em uma vivência bem sucedida em todas as dimensões da experiência do estudante nesse contexto: cognitiva, vocacional, pessoal, cultural e social. Embora nas últimas duas décadas tenha havido um aumento dos estudos descrevendo o processo de desenvolvimento vocacional dos estudantes universitários no país (ALMEIDA \& DINIZ, 2005; ARAÚJO, 2008; MAGALHÃES, 2013; MOGNON \& SANTOS, 2013; POLYDORO \& GUERREIRO-CASANOVA, 2010; SAMPAIO et. al., 2011; SARRIERA et. al., 2012; SILVA, COELHO \& TEIXEIRA et. al., 2008; TEIXEIRA, 2013; entre outros), ainda há pouca ênfase da literatura em estudos ligados ao tema da experiência universitária no meio do curso, uma vez que a maioria dos estudos concentra-se nos períodos de transição (saída da escola e entrada na universidade e/ou saída da universidade e entrada no mercado de trabalho).

Muitos estudiosos têm buscado compreender melhor o estudante do ensino superior, bem como seu processo de interação com a instituição e as mudanças decorrentes da diversidade de experiências propiciadas nessa relação. O presente artigo pretende contribuir com a temática discutindo a relação do aluno no período intermediário da graduação com seu curso, partindo de uma experiência de estágio em orientação profissional realizado na Universidade Federal de Santa Catarina (UFSC). A reflexão sobre a problemática em questão foi despertada pelo caso de uma participante de um dos grupos de orientação profissional voltados a estudantes universitários realizados durante o estágio. A fragilidade da relação da estudante com seu curso foi a questão norteadora. No decorrer dos encontros, a participante trazia sentimentos ambíguos em relação ao curso: de um lado, havia identificação e, de outro, experimentava insegurança. Ali, ela encontrou espaço de acolhimento, onde a naturalidade de tais sentimentos e o reconhecimento através da narrativa de seus pares teve lugar. O relato mais detalhado do caso ilustrará e dará início à discussão que se pretende abordar neste trabalho. Contudo, inicialmente é fundamental a 
apresentação do escopo teórico que orienta e operacionaliza o presente estudo e a prática profissional.

Nas últimas décadas, desenvolveram-se teorias que abordaram o desenvolvimento vocacional em uma perspectiva mais ampla do desenvolvimento psicológico, em contrapartida aos primeiros conceitos, cujo entendimento estava circunscrito a características e traços do sujeito (MONTEIRO \& GONÇALVES, 2011). As abordagens baseadas no modelo Evolutivo, com origem nos trabalhos de Donald Super, trouxeram grandes contribuições para o campo. Este modelo propõe um enfoque no processo de escolha e não no resultado propriamente dito; preocupa-se em compreender o contexto de desenvolvimento do orientando e em auxiliá-lo no processo de autoconhecimento de suas condições, possibilidades e limitações (MONTEIRO \& GONÇALVES, 2011; SPARTA, BARDAGI \& TEIXEIRA, 2006; TEIXEIRA, 2008).

Oliveira, Guimarães e Dela Coleta (2006) salientam o pioneirismo de Super em compreender o comportamento vocacional pelo prisma do desenvolvimento humano. A escolha não é encarada como fato pontual e isolado, e sim resultante de um processo que ocorre ao longo da vida do indivíduo. Nessa perspectiva teórica, a escolha profissional envolve a formação de um autoconceito, processo que se inicia na infância e está relacionado com o desenvolvimento de uma identidade profissional.

Pode-se dizer que Super inovou na área da orientação vocacional e de carreira ao dar ênfase à noção de desenvolvimento da carreira ao longo do ciclo vital e à observação do comportamento vocacional do indivíduo no decorrer do tempo, em congruência com as demais dimensões do desenvolvimento humano (LASSANCE \& SARRIERA, 2009; OLIVEIRA, MELO-SILVA \& DELA COLETA, 2012; TEIXEIRA, 2008). Por compreender de forma abrangente a questão vocacional, ao considerar tanto características pessoais quanto contextuais e suas inter-relações, optou-se pela teoria desenvolvimental como base norteadora deste trabalho.

Para a compreensão da discussão proposta, a questão do comportamento exploratório e do autoconceito, aspectos centrais na abordagem desenvolvimental, merecem destaque. A atividade exploratória refere-se aos comportamentos sistemáticos e intencionais que fornecem informações tanto interiores quanto exteriores ao indivíduo, auxiliando-o na resolução de problemas, realização de escolhas e organização da experiência de maneira geral, sendo constantes ao longo de toda a vida e intensificando-se em períodos de mudanças pessoais ou profissionais (TEIXEIRA, BARDAGI \& HUTZ, 2007; TEIXEIRA \& DIAS, 2011).

Trata-se de comportamentos que exigem curiosidade, iniciativa, observação, predisposição à exposição, experimentação, teste de hipóteses e desempenho de papéis, e permitem a reunião de informações essenciais à formação do autoconceito, que pode ser 
entendido, por sua vez, como o conjunto de percepções que a pessoa possui sobre si mesma, construídas conforme o indivíduo vai desempenhando diferentes papéis sociais e ocupacionais e referentes às dimensões das aptidões, interesses, valores e crenças tanto de si quanto das possibilidades e das oportunidades de vida do sujeito (LASSANCE \& SARRIERA, 2009; TEIXEIRA, 2008).

Apesar do período anterior à entrada na universidade ser propício a um maior investimento em atividades exploratórias, o período da graduação como um todo demanda do aluno certo nível de comportamento exploratório que possa subsidiar as decisões tomadas ao longo do curso e a formulação de projetos profissionais (SILVA, COELHO \& TEIXEIRA, 2013). Estudos na área têm confirmado as relações positivas entre exploração e decisão de carreira (GAMBOA, PAIXÃO \& JESUS, 2011; MAGALHÃES, 2013; MOGNON \& SANTOS, 2013). As atividades exploratórias objetivam delinear preferências do sujeito, sendo fundamentais para a realização de escolhas profissionais maduras e realistas e favorecem, consequentemente, a entrada no mercado de trabalho de maneira mais segura; já o autoconceito é relativo a características vocacionais que o sujeito percebe em si e levam-no a se identificar com determinadas ocupações. Vale destacar ainda que o comportamento de busca por informações de si e do mundo profissional estão interligados e devem caminhar juntos, pois o autoconhecimento dos valores e habilidades leva a procura por experiências profissionais que satisfaçam essas características e a exploração do ambiente, por sua vez, acaba impelindo o sujeito à análise de seus próprios valores e interesses.

Outro fator relevante para a Orientação Profissional, nesse sentido, refere-se à influência que os valores e crenças pessoais, assim como os meios familiar e social, estereótipos e preconceitos, exercem na qualidade e quantidade de atividades de busca por informações profissionais, uma vez que a assimilação de informações parciais ou equivocadas pode levar à construção de projetos profissionais estereotipados e inconsistentes (SPARTA, BARDAGI \& ANDRADE, 2005; TEIXEIRA, 2002). No caso dos jovens, a informação sobre o mundo do trabalho é fundamental no processo de orientação profissional, pois promove a conscientização do indivíduo sobre a influência que os fatores externos exercem na escolha. Oliveira et. al.., (2006) realçam, entretanto, a necessidade do orientador em avaliar a prontidão do orientando para utilizar o conhecimento que possui sobre suas habilidades e interesses de maneira eficaz no seu processo de escolha profissional. Nesse sentido, o orientador profissional facilita o processo de escolha do orientando, auxiliando-o na tomada de consciência de si mesmo e do mundo.

Com relação ao ensino superior, dados do Instituto Nacional de Estudos e Pesquisas Educacionais Anísio Teixeira (INEP, 2010 apud MAGALHÃES, 2013) revelam média de 40\% no 
índice de evasão dentre instituições públicas e privadas. $O$ crescente número de estudos envolvendo a necessidade da oferta de serviços institucionais de apoio e orientação ao estudante universitário tem demonstrado a importância desse suporte para uma integração acadêmica e social positiva ao contexto da universidade (BASSO et. al., 2013; BISINOTO \& MARINHOARAÚJO, 2011; SARRIERA et. al., 2012; PINTO \& CASTANHO, 2012). Bisinoto, MarinhoAraújo \& Almeida (2014), ao traçarem um panorama dos serviços de psicologia ofertados em instituições de ensino superior no Brasil e em Portugal, apontaram a compreensão da necessidade de intervenções de caráter preventivo e a consequente organização de programas sustentados nesse enfoque como modelo emergente.

Ao contrário do período inicial do curso, caracterizado por um estado de exaltação frente ao sucesso no vestibular, o ingresso na universidade e às expectativas quanto ao curso, estudos mostram que o período intermediário é marcado pelos questionamentos dos estudantes quanto às escolhas que fizeram e à própria universidade, gerando muitas vezes decepção com o curso, professores, instituição e a possibilidade de apostar em uma nova escolha; aqui, a importância da participação em atividades acadêmicas parece ser determinante para uma visão mais positiva ou negativa da formação (BARDAGI \& HUTZ, 2010, 2012; LUNA et. al., 2014; SILVA, COELHO \& TEIXEIRA, 2013; TEIXEIRA et. al., 2008).

Essa maior frequência de alunos insatisfeitos com o curso a partir da fase intermediária pode estar associada à menor tolerância do aluno frente às dificuldades enfrentadas no curso e maior preocupação com a transição para o mercado de trabalho. Por sua vez, a insatisfação com o curso está associada a um engajamento menor em atividades acadêmicas e maior probabilidade de evasão (BASSO et. al., 2013; BARDAGI \& HUTZ, 2012; MAGALHÃES, 2013, SARRIERA et. al., 2012), enquanto atividades de planejamento e exploração de carreira se correlacionam positivamente com satisfação com o curso, comprometimento com a carreira, satisfação de vida e auto avaliação positiva do rendimento acadêmico.

Um estudo exploratório realizado com estudantes universitários em meio de curso por Bardagi, Lassance e Paradiso (2003) revelou que, apesar da maior parte dos estudantes afirmarem ter pensado em desistir ou mudar de curso na fase inicial, uma parcela significativa deles mencionou pensar sobre isso por todo o tempo. A pesquisa também encontrou interesse dos alunos em planejar e construir projetos profissionais desde o período intermediário da formação. Oliveira e Dela Coleta (2008) encontraram dados semelhantes ao pesquisarem sobre maturidade de carreira em universitários, ressaltando que após dedicarem-se intensamente a atividades de exploração para fazer uma escolha profissional, estudantes ingressantes diminuem o empenho em tais atividades assim que são aprovados no vestibular, e voltam a preocupar-se novamente no 
meio e final do curso, quando sentem necessidade de definir área de atuação para estágio ou traçar planos de carreira para inserção no mercado de trabalho.

As autoras ainda constataram que universitários participantes de atividades de orientação de carreira, em comparação com aqueles que não participaram, apresentam maiores níveis de maturidade de carreira, um indicativo dos benefícios de atividades como essa, uma vez que podem oferecer suporte ao estudante ingressante no sistema de ensino superior, em transição para o mercado de trabalho ou mesmo tendo que tomar decisões profissionais ao longo da graduação, como é o caso do aluno de fase intermediária.

Nesse sentido, compreender melhor as características e necessidades dos estudantes universitários, principalmente no período intermediário por todo o exposto acima, é fundamental para que a universidade estruture serviços de apoio e orientação ao estudante procurando promover envolvimento institucional e desenvolvimento vocacional, pessoal, social e cultural de seus alunos (ALMEIDA, SOARES \& FERREIRA, 2002). A descrição do caso e do atendimento realizados abaixo procura exemplificar as inseguranças do aluno de fases intermediárias e os benefícios de uma intervenção vocacional neste período.

\section{RELATO DO ATENDIMENTO DE GRUPO NO SERVIÇO DE ORIENTAÇÃO PROFISSIONAL DO LIOP/UFSC}

O serviço de Orientação Profissional é oferecido gratuitamente à comunidade pelo Laboratório de Informação e Orientação Profissional (LIOP), um projeto de extensão universitária que funciona nas dependências do SAPSI (Serviço de Atenção Psicológica) do Departamento de Psicologia da UFSC, há cerca de 20 anos, sendo um dos pioneiros da área no Brasil (SOARES, 2010). Os atendimentos são realizados por estudantes em estágio obrigatório curricular ou extracurricular ou por bolsistas de extensão, supervisionados por professores da área. A Orientação Profissional é dirigida a adolescentes pré-vestibulandos, alunos universitários desistentes ou que queiram refletir sobre sua permanência no curso e adultos que buscam planejamento de carreira ou auxílio para transições na vida profissional, e pode acontecer nas modalidades individual ou de grupo.

O atendimento em grupo que originou este estudo contemplava estudantes desistentes de curso de nível superior e estudantes insatisfeitos com o curso escolhido, e foi realizado em sete encontros de duas horas cada, além de uma entrevista individual inicial e outra ao final do processo. Cumpre ressaltar que os encontros eram planejados em supervisão de acordo com a 
situação problema apresentada como emergente grupal no encontro anterior. Através de autobiografias, questionários, desenhos, dinâmicas, compartilhamento e debates em grupo, dentre outras técnicas compatíveis com a abordagem desenvolvimental utilizada como base para o trabalho (LASSANCE, 2010), buscou-se integrar as características pessoais e contextuais dentro de um panorama do desenvolvimento global dos indivíduos, considerando os diversos aspectos que podem influenciar o processo de escolha e colaborando para uma visão mais ampla das questões vocacionais de cada participante. O grupo foi composto por seis participantes. As informações gerais de cada participante estão dispostas na Tabela 1.

\begin{tabular}{|c|c|c|c|c|c|}
\hline Participante & Sexo & Idade & $\begin{array}{l}\text { Curso } \\
\text { Inicial }\end{array}$ & $\begin{array}{l}\text { Semestres } \\
\text { cursados }\end{array}$ & Decisão Final \\
\hline P1 & $\mathrm{M}$ & 19 & $\begin{array}{l}\text { Engenharia de } \\
\text { Produção }\end{array}$ & 3 & Fonoaudiologia \\
\hline P2 & M & 21 & $\begin{array}{l}\text { Ciência } \\
\text { Computação }\end{array}$ & 4 & Permaneceu \\
\hline P3 & M & 21 & Design Gráfico & 5 & Administração \\
\hline P4 & $\mathrm{F}$ & 20 & $\begin{array}{ll}\text { Design } & \text { de } \\
\text { Produto } & \end{array}$ & 1 & Fonoaudiologia \\
\hline P5 & $\mathrm{F}$ & 20 & Direito & 3 & Permaneceu \\
\hline P6 & F & 20 & Jornalismo & 4 & Permaneceu \\
\hline
\end{tabular}

Fonte: elaborado pelas autoras

Iniciou-se o processo de orientação profissional com uma entrevista individual, cujo objetivo era explorar os motivos da procura pelo serviço e um primeiro contato com a história individual de cada estudante que integraria o grupo. Apesar da heterogeneidade dos estudantes em seus cursos de origem, os motivos pelos quais procuraram o serviço podem ser agrupados em dois subtipos: alguns verbalizavam não se identificar com a profissão e outros buscavam uma confirmação da escolha, inseguros com o futuro profissional. Destaca-se também o fato de todos os participantes, com exceção de P4, encontrarem-se na fase intermediária dos cursos quando procuraram pelo serviço.

Exceto no caso de P3, que apresentou baixo grau de implicação ao longo de todo o processo de $\mathrm{OP}$, os demais participantes chegaram ao último encontro com perspectivas coerentes de tomadas de decisão em relação ao que significaram a partir das vivências em grupo. P2 e P5 questionaram suas escolhas durante o processo; contudo, foram percebendo que a dúvida estava sendo movida mais devido a dificuldades pedagógicas do que a uma não identificação com a profissão. P1, P3 e P4 tinham claro desde o início que não se identificavam com a profissão escolhida e buscaram, então, explorar alternativas. E o caso de P6, inicialmente motivador da produção deste trabalho, será mais bem descrito adiante. 


\section{Caso Gabriela (P6)}

A análise aqui desenvolvida, conforme explicitado anteriormente, abarca o processo de Orientação Profissional de uma participante desse grupo em específico. Assim, o relato a seguir foca o percurso desta participante, a quem se convencionou chamar Gabriela, ao longo dos atendimentos grupais e das entrevistas individuais. As produções discursivas utilizadas foram extraídas de transcrições feitas durante e após os atendimentos e entrevistas pelos dois orientadores do grupo. Nesse sentido, cabe ressaltar que ao preencherem a ficha de inscrição no serviço, os participantes assinam um Termo de Consentimento Livre e Esclarecido, optando por autorizar a utilização de seus materiais como dados para pesquisas e comunicações científicas, o que ocorreu com Gabriela.

$\mathrm{Na}$ entrevista inicial, Gabriela afirmou sua dúvida em sair do curso de Jornalismo, mostrou-se desanimada com as perspectivas profissionais que visualizava até então e disse pensar na possibilidade de outro curso cuja carreira, segundo ela, fosse mais promissora e segura em termos de sucesso profissional. A estudante estava no terceiro semestre, dando-se conta do seu desânimo com o curso, e começou a pensar em outras áreas, como Direito, Arquitetura, Pedagogia e Publicidade. Através da técnica da Linha da Vida (LASSANCE, 2010), Gabriela expôs ao grupo seus sentimentos de insatisfação com o curso no geral e com alguns professores em particular, mas também seus interesses por algumas áreas específicas da profissão, como a redação e o rádio; acrescentou que fora por admiração aos jornalistas que via na televisão que escolheu prestar vestibular para o curso.

$\mathrm{Na}$ época, lembra que procurou saber superficialmente sobre o currículo, mas não buscou informações sobre a profissão ou o mercado de trabalho da área. Ao avaliar as dimensões acadêmicas, no segundo encontro, ela disse que tinha antes uma "visão mágica do Jornalismo", mas ficou mais realista dentro do curso, descobriu ali a rotina de trabalho do profissional, a estrutura da grade curricular e a princípio não gostou, mas acabou se acostumando ao "ritmo louco" que o curso tem - aulas em horários irregulares e trabalhos até tarde da madrugada, e conta: "Não sei se me adaptaria a um curso com aulas certinhas".

Contudo, não gostava dos professores e não sentia harmonia na relação com os colegas. "Gostaria de sair mais com eles, mas não sinto que é a minha turma.(...) Ainda saio mais com minhas amigas do Ensino Médio". Quanto aos professores, dizia que o comum é ouvi-los "falando mal" da profissão e da linha de atuação de outros colegas. Sobre o curso, achava-o "fraco", não sentia que estava aprendendo e duvidava que houvesse melhoria nesse sentido até o fim da graduação. "O professor 
dá a aula e parece que en já sabia. Sei que não é isso, mas parece que eu tô ouvindo o óbvio!". O último fator discutido, porém, mostrou-se o determinante maior da vontade de Gabriela de sair do curso. "Tenho medo de me arriscar", disse referindo-se à insegurança que a profissão lhe transmitia financeiramente (arriscar terminar a faculdade e talvez. conseguir um bom emprego e talvez. conseguir ganhar dinheiro).

Ainda, mostrou grande frustração com o que conheceu na faculdade sobre a atuação do jornalista e os modos de trabalho dessa área e, quando indagada por outro participante sobre qual seria sua profissão dos sonhos, ela respondeu que seria trabalhar com um estilo jornalístico mais livre, sem tanta pressão, podendo escrever e publicar sobre o que quisesse. "Não anotei nada relacionado ao jornalismo", disse Gabriela quando preencheu um inventário de habilidades e interesses e acrescentou: "Minha mão fugia das habilidades que eu via que tinham a ver com o jornalismo, vi que acabei colocando coisas bem distantes dele". Os cursos que ela tinha trazido como possibilidades na primeira entrevista voltaram à cena nessa discussão, lembrando ela que tinha conhecido o trabalho de uma psicopedagoga e que havia ficado bastante interessada na profissão. Mas aí novamente vinha a questão do medo de se arriscar, sair do curso na metade, que o tempo estava passando e ela ia ficar para trás.

A oportunidade de se imaginar em outras profissões que fossem coerentes com o que Gabriela havia sinalizado no encontro anterior fora proporcionada através da técnica do “imaginar-se em um dia de trabalho daqui a dez anos", mas não aconteceu. Ao contrário, ela imaginou-se levando uma rotina de jornalista: “Achei bem fácil pensar numa rotina. Talvez. por só conhecer a rotina de jornalista e não de outras profissões, mas só consegui me imaginar jornalista". Terminou, porém, com o choque da realidade, dizendo que as coisas não eram assim, que ela sabia que havia muita competitividade, enganação e brigas entre os colegas de trabalho, que o tempo disponível para escrever uma matéria, por exemplo, era curtíssimo e inviabilizava uma pesquisa de qualidade sobre o tema, forçando os profissionais a lançarem matérias superficiais e sem credibilidade e que, inclusive, ela já tivera essa experiência no seu próprio estágio.

Toda essa exposição movimentou sentimentos bastante delicados de Gabriela em relação a sua visão sobre a profissão de jornalista e ali ela encontrou lugar para desabafar também como se sentia mal em ouvir as angústias e sofrimentos de vida das pessoas e seu papel limitar-se a entendê-las como "meros personagens da matéria", em ter que cortar as relações estabelecidas com as pessoas assim que a matéria fica pronta e utilizar os depoimentos de maneira parcial e direcionado ao tom que se deseja dar à reportagem. Ela disse que gostava muito da rotina da profissão, mas as condições às quais deveria se submeter a estavam deixando extremamente 
desmotivada em seguir adiante. "Tem que ser absurdamente bom pra conseguir uma abertura para um jornalismo mais bumano", disse ela.

O processo do grupo já estava caminhando da identificação de interesses para a exploração de informações profissionais nas áreas correspondentes e o quinto encontro seria destinado a pensar possibilidades de mercado, localizando pessoas-referência que pudessem fornecer dados concretos de trabalho, e como eles se visualizavam em tais campos. Nesse encontro, porém, Gabriela faltou. E no seguinte, quando ela poderia recuperar tal discussão, também. Gabriela veio para o último encontro dizendo-se ainda muito confusa.

Ao expor seu cartaz para o grupo, mostrou um ponto de interrogação e falou que representava sua grande dúvida: não sabia se o jornalismo era mesmo seu lugar, que naquela semana estava bastante decepcionada, pois havia tido a oportunidade de acompanhar a realização de uma matéria televisiva para um jornal da maior emissora da cidade e frustrou-se ao ver como era "amador" a maneira de fazer aquilo que ela via na televisão e achava "o máximo". Nessas horas, a vontade de abandonar tudo virava quase uma certeza, não fosse o medo que sentia: estava na quarta fase e achava que já tinha perdido muito tempo ali, era "tarde pra comeşar outra coisa" e, se saísse, apostaria em quê?

Nesse sentido, a palavra "resistência” que estava em seu cartaz expressou bem esses anseios - resistia em ficar no jornalismo por todas as queixas que apontava, mas resistia também em sair em função de perceber-se identificada com as tarefas da profissão e as possibilidades que ela apresentava.

$\mathrm{Na}$ entrevista final foi apontado o movimento de vai-e-vem que ela percorreu entre a desistência e a identificação com o curso de jornalismo ao longo dos encontros: imaginando-se jornalista num futuro ideal, identificando atividades que seriam satisfatórias, mas procurando assinalar habilidades distantes às requeridas na profissão no inventário de habilidades, por exemplo. Falou-se também sobre a percepção de que muitas de suas más impressões acerca da carreira de jornalismo poderiam estar contaminadas por vivências particulares de professores daquele departamento. Ainda, poderia ser reflexo de características locais do mercado de trabalho para profissionais do jornalismo, e que enriqueceria e poderia tornar esse momento de decisão mais consciente se ela extrapolasse os muros da universidade e explorasse mais informações sobre o campo de atuação nacionalmente, conhecendo mais possibilidades da área e desmitificando algumas noções cristalizadas que foram internalizadas ao longo da graduação. Por fim, relatamos os dois sentidos apreendidos por nós a partir da palavra "resistência" no cartaz, que pareciam melhor definir seu momento no processo de escolha e queríamos saber se algum fazia 
mais sentido para ela. A resistência era para sair, disse ela, porque não se pensava em outro curso. Ao final do processo, Gabriela permaneceu na graduação inicial.

\section{RESULTADOS E ANÁLISES}

Este trabalho não se configura como um estudo de caso, mas busca, a partir do exemplo de um atendimento de orientação profissional com uma estudante universitária, refletir sobre as relações estabelecidas entre o aluno e o curso, no período intermediário da graduação, e apontar alguns aspectos a considerar em intervenções voltadas a este público.

No contexto da orientação vocacional, entendendo que a escolha não é processo pontual, mas desenvolvida ao longo do tempo, é possível entender que Gabriela não tivesse apresentado, até o momento da primeira escolha, comportamentos exploratórios em quantidade e qualidade suficientes que pudessem dar solidez à formação de um autoconceito que expressasse seus reais valores, interesses e habilidades. Dessa maneira, se, por um lado, Gabriela estava descontente com o jornalismo devido, dentre outros elementos, a um fraco desempenho em atividades exploratórias, por outro, o medo de sair encontrava respaldo justamente em uma percepção pobre de suas características vocacionais, que não permitiam que se identificasse o bastante com esta ou com outras ocupações.

No entanto, mesmo durante a graduação, Gabriela explorou muito pouco, contentandose com as informações e valores transmitidos pelos professores do curso, deixando de buscar atividades extracurriculares ou conversar com outros profissionais e estudantes da área. Nesse sentido, a partir do caso ilustrado, fica claro como investir e manter comportamento exploratório é necessário ao longo de toda a vida, inclusive durante o período da graduação, confirmando os estudos que apontam correlação positiva entre comportamento exploratório e nível de decisão de carreira (GAMBOA, PAIXÃO \& JESUS, 2011; MOGNON \& SANTOS, 2013), já que permitirá ao sujeito que vá delineando preferências e depois, dentro da graduação, especificando-as com o objetivo de construir projetos e atingir o mercado de trabalho.

Outro ponto que merece atenção refere-se ao momento da procura pelo serviço de Orientação Vocacional. No caso de Gabriela e de muitos colegas do grupo, aconteceu no período intermediário, em um contexto de descontentamento com a graduação e incertezas quanto ao investimento em outra área profissional. Este período é citado consistentemente pela literatura como de questionamentos em relação à escolha feita e à estrutura da própria universidade, apontando-o como um momento propício ao aparecimento de dúvidas e que pode ser vivido de maneira bastante conflituosa (SARRIERA et. al., 2012; LASSANCE \& GOCKS, 1995; MELOSILVA \& REIS, 1997; TEIXEIRA, 2002). 
Gabriela queixava-se principalmente da frustração com a imagem que os professores e alguns colegas passavam sobre o curso, da falta de perspectivas de fazer 'o jornalismo que queria' e da visão estereotipada do jornalista 'interessado apenas na matéria e não nas pessoas'. Estas queixas novamente podem ser relacionadas à baixa exploração vocacional e à adoção de valores e crenças estereotipadas, muitas vezes fruto de experiências ou percepções de terceiros (professores, colegas). Aqui, Gabriela não conseguia integrar sua auto percepção em termos de interesses e valores pessoais ao que recebia de informações externas sobre a profissão que escolhera; isso fragilizava sobremaneira sua construção de autoconceito e sua decisão de carreira.

Como apontado por Lassance e Sarriera (2009) e Teixeira, Bardagi e Hutz (2007), a exploração implica necessariamente comportamentos que exigem curiosidade, iniciativa, observação, predisposição à exposição, experimentação, teste de hipóteses e desempenho de papéis, a fim de consolidar uma visão de si mesmo e do mundo ocupacional mais pessoal e realista, processo no qual Gabriela não havia se engajado.

Ao falar sobre o conteúdo do curso, talvez essa reclamação não seja exclusiva do curso de jornalismo, mas comum a muitos cursos universitários no que se refere a currículos desintegrados e fragmentados, que não proporcionam um senso de unidade, a uma falta de comunicação entre os professores e, por fim, à falta de integração teoria-prática (SOARES, 2002; FIOR \& MERCURI, 2009). Muitas vezes, as disciplinas curriculares e os conteúdos ministrados falham em transmitir aos alunos como determinado conhecimento ou aula podem ser relacionados com o que eles farão enquanto profissionais e em que medida ele é útil para a futura profissão daqueles estudantes.

Quanto à preocupação de Gabriela com a transição para o mercado de trabalho, também a certeza que expressava na correlação jornalista - má remuneração - péssimas condições de trabalho fora paulatinamente internalizada e fortificada ao ouvi-la repetidamente ao longo dos semestres. Para ela, trabalhar com um estilo mais humano, que promovesse maior contato e possibilidade de resolução de problemas e sofrimentos das pessoas era exceção e só chegava lá quem tivesse um desempenho excepcional. A relação de Gabriela com a carreira era ainda revestida por um ideal mágico do emprego perfeito, onde só existiam pontos positivos, e isso estava aumentando o abismo entre suas expectativas e o que encontrava na realidade, provocando sentimentos ainda maiores de frustração com a profissão. Abordamos a questão como ilustração de escolhas que não se fundamentam em informações efetivas acerca da profissão, desdobrando-se em disparidade entre o que se pensava que era e o que realmente é.

Aqui, parece que o aluno de fases intermediárias confia que as informações já lhe foram passadas, não há nada mais por descobrir, e se cristalizam percepções construídas durante os 
semestres iniciais. Afinal, o que há de novo para quem já está há dois anos na graduação? Para romper com esta tendência à acomodação, salienta-se novamente a necessidade da exploração, também como uma atividade fomentada pela própria instituição, através do estímulo dos professores e da oferta de atividades extraclasse. A importância da participação em atividades acadêmicas como determinante para uma visão mais positiva ou negativa da formação já foi sistematicamente descrita na literatura (BARDAGI \& HUTZ, 2010; LASSANCE \& GOCKS, 1995; MELO-SILVA \& REIS, 1997).

Contudo, apesar de suas inúmeras queixas, existia uma identificação com o ofício, com a rotina de ser jornalista, mas que estava sendo sobrepujada pelos impactos negativos enfrentados na graduação. Gabriela não tinha referenciais positivos de trabalho dentro do jornalismo, havia a necessidade de ampliar seu conhecimento acerca das possíveis áreas de atuação e seu autoconhecimento no sentido de quais habilidades gostaria de exercitar profissionalmente e em que área do jornalismo isso seria possível; assim, a elaboração de projetos profissionais mais maduros e coerentes se daria através do aumento do nível das atividades exploratórias de Gabriela, incentivando-a a entrevistar professores, profissionais de diferentes campos de uma mesma área de conhecimento, apostando em estágios, participando de eventos, congressos e apropriando-se das ferramentas de busca que a internet propicia exclusivamente nesse assunto.

Ainda, conhecendo mais sobre as atividades de interesse, iria se deparar com realidades na qual os profissionais não fazem exclusivamente o que mais gostam, mas que certamente teriam que despender energia com algumas atividades do seu fazer cotidiano pelas quais não se interessavam, mas que compunham o exercício profissional, sem invalidar a identificação pessoal com a tarefa. Extrapolar os muros da universidade e buscar novas referências dentro do jornalismo era essencial para ampliar os conceitos e valores de Gabriela a respeito da profissão, desconstruir preconceitos e basear suas decisões em informações concretas acerca do mercado de trabalho.

Sob esse ângulo, os atendimentos de orientação profissional cumpriram papel fundamental ao promover discussões sobre processo de escolha, vivência acadêmica, projetos de carreira e mercado de trabalho, além de prover lugar de acolhimento aos sentimentos de frustração e indecisão. Foi importante discutir, tanto com Gabriela como com o grupo todo, as nuances da relação aluno-universidade ao longo do tempo, indicando os aspectos que são importantes como mediadores dessa relação (contato com professores, atividades acadêmicas, qualidade da escolha inicial, contato com colegas, desempenho acadêmico, etc.).

Entre inúmeros desafios pessoais e institucionais com os quais os jovens se deparam ao ingressar no ensino superior e ao longo de todo o seu percurso, o trabalho de Orientação 
Profissional vem se constituindo como um importante recurso de auxílio aos estudantes que se sentem insatisfeitos em seus cursos e procuram uma confirmação da escolha ou nova opção (GAMBOA, PAIXÃO \& JESUS, 2011; PINTO \& CASTANHO, 2012).

\section{CONSIDERAÇÕES FINAIS}

O presente artigo buscou contribuir para o entendimento de que o período intermediário de formação universitária deve receber a mesma atenção que pesquisadores e profissionais da área da orientação profissional dão aos períodos de transição. Como sugerem o caso apresentado e as indicações da literatura, a relação estudante-universidade envolve uma rede de interações dinâmica e complexa entre fatores relacionados ao estudante, à instituição e aos eventos externos.

Mais precisamente, quatro âmbitos têm sido definidos quando se fala em vivência no ensino superior: o acadêmico, referente ao sistema de ensino e à estratégia curricular; o social, que abrange as relações com professores e colegas; o pessoal, envolvendo valores, interesses e autoconceito; e, por fim, o vocacional, que se refere à identidade vocacional e ao compromisso com o curso e a carreira (ALMEIDA \& SOARES, 2003). No caso apresentado as quatro dimensões compunham um quadro geral de descontentamento com o curso escolhido, muito em função do pouco conhecimento realista acerca do curso e das poucas experiências acadêmicas vividas pela aluna em questão, e o serviço de orientação profissional foi essencial para que a estudante identificasse onde estavam os pontos críticos e ficasse mais consciente de suas implicações e possibilidades.

Nesse sentido, apoiando-se no argumento de que é dever da universidade promover o desenvolvimento integral de seus alunos, preparando-os para atuarem na sociedade de forma responsável e consciente, a instituição tem papel fundamental na promoção de um ambiente que possibilite maior confiança ao estudante, estimulando-o ao desenvolvimento e ao gerenciamento satisfatório dos inúmeros desafios com os quais se depara ao ingressar na vida universitária. Para que isso se concretize, é preciso que as instituições se organizem, estruturando políticas de atuação que garantam a implementação e a utilização efetiva de serviços de apoio ao estudante universitário, bem como de um ambiente acadêmico acolhedor. 


\section{REFERÊNCIAS}

ALMEIDA, Leandro S.; DINIZ, Antonio M. Escala de Integração Social no Ensino Superior (EISES): Metodologia de construção e validação. Análise Psicológica, v. 4, n. 23, p. 461-476. 2005.

ALMEIDA, Leandro S.; SOARES, Ana Paula. Os estudantes universitários: Desenvolvimento Psicossocial. In: MERCURI, Elizabeth; POLYDORO, Soely Aparecida Jorge (Orgs.). Estudante Universitário: características e experiências de formação. Taubaté: Cabral Editora e Livraria Universitária, 2003. p. 15-40.

ALMEIDA, Leandro S.; SOARES, Ana Paula; FERREIRA, Joaquim Armando. Questionário de vivências acadêmicas (QVA-r): Avaliação do ajustamento dos estudantes universitários. Avaliação Psicológica, v.1, n.2, p. 81-93, nov. 2002.

ARAUjO, Uajará Pessoa et. al. Expectativas e estratégias de ação em relação à inserção profissional. Revista Brasileira de Orientação Profissional, São Paulo, v. 9, n. 2, p. 81-96, dez. 2008.

BARDAGI, Marucia Patta; HUTZ, Cláudio Simon. Satisfação de vida, comprometimento com a carreira e exploração vocacional em estudantes universitários. Arquivos Brasileiros de Psicologia, v. 62, n.1, p. 159-170. 2010.

Rotina acadêmica e relação com colegas e professores: impacto na evasão universitária. Psico, v. 43, n. 2, p. 174-184, abr/jun. 2012.

BARDAGI, Marucia Patta; LASSANCE, Maria Celia Pacheco; PARADISO, Ângela Carina. Trajetória acadêmica e satisfação com a escolha profissional de universitários em meio de curso. Revista Brasileira de Orientação Profissional, São Paulo, v.4, n.1/2, p. 153-266, dez. 2003.

BASSO, Cláudia et. al.. Organização de tempo e métodos de estudo: Oficinas com estudantes universitários. Revista Brasileira de Orientação Profissional, v. 14, n. 2, p. 277-288, 2013.

BISINOTO, Cynthia; MARINHO-ARAÚJO, Claisy Maria. Psicologia escolar na educação superior: Atuação no Distrito Federal. Psicologia em Estudo, v. 16, n. 1, p. 111-122, 2011.

BISINOTO, Cynthia; MARINHO-ARAÚJO, Claisy; ALMEIDA, Leandro. Serviços de psicologia na educação superior: panorama no Brasil e em Portugal. Revista de Estudios e Investigación en Psicología y Educación, v. 1, n. 1, p. 82-90, 2014.

FERREIRA, Joaquim Armando; ALMEIDA, Leandro S.; SOARES, Ana Paula. Adaptação acadêmica em estudante do $1^{\circ}$ ano: diferenças de gênero, situação de estudante e curso. PsicoUSF, Itatiba, v.6, n.1, p. 01-10, jan/jun. 2001.

FIOR, Camila Alves; MERCURI, Elizabeth. Formação universitária e flexibilidade curricular: importância das atividades obrigatórias e não obrigatórias. Psicologia da Educação, São Paulo, n.29, p. 191-215, dez. 2009. 
GAMBOA, Vitor; PAIXAO, Maria Paula; JESUS, Saúl Neves de. A eficácia de uma intervenção de carreira para a exploração vocacional. Revista brasileira de orientação profissional, São Paulo, v. 12, n. 2, p. 153-164, dez. 2011.

LASSANCE, Maria Celia Pacheco (Org.). Técnicas para o trabalho de orientação profissional em grupo. Porto Alegre: Editora da UFRGS. 2010. 274 p.

LASSANCE, Maria Celia Pacheco; GOCKS, Anelise. A formação da identidade profissional em universitários: a questão da prática. Anais do II Simpósio Brasileiro de Orientação Vocacional e Ocupacional. São Paulo: ABOP, 1995. p. 65-70.

LASSANCE, Maria Celia Pacheco; GOCKS, Anelise; FRANCISCO, Deise J.. Escolha profissional em estudantes universitários: estilos de escolha. Anais do I Simpósio Brasileiro de Orientação Vocacional e Ocupacional. São Paulo: ABOP, 1993.

LASSANCE, Maria Celia Pacheco; SARRIERA, Jorge Castellá. Carreira e saliência dos papéis: Integrando o desenvolvimento pessoal e profissional. Revista Brasileira de Orientação Profissional, São Paulo, v.10, n.2, p. 15-31. 2009.

LUNA, Iúri Novaes et. al.. Empresas juniores como espaço de desenvolvimento de carreira na graduação: reflexões a partir de uma experiência de estágio. Revista Psicologia, v. 14, n. 4, p. 441-451, 2014.

MAGALHAES, Mauro de Oliveira. Sucesso e fracasso na integração do estudante à universidade: um estudo comparativo. Revista Brasileira de Orientacão Profissional, São Paulo, v. 14, n. 2, p. 215-226, dez. 2013.

MELO-SILVA, Lucy Leal; REIS, Vera Aparecida Bertocco dos. A identidade profissional em estudantes do curso de Psicologia: Intervenção através da técnica de grupo operativo. Anais do III Simpósio Brasileiro de Orientadores Profissionais. Canoas, RS: ABOP, 1997. p. 57-65.

MOGNON, Jocemara Ferreira; SANTOS, Acácia Aparecida Angeli dos. Relação entre vivência acadêmica e os indicadores de desenvolvimento de carreira em universitários. Revista Brasileira de Orientação Profissional São Paulo, v. 14, n. 2, p. 227-237, dez. 2013.

MONTEIRO, André Magalhães; GONÇALVES, Carlos Manoel. Desenvolvimento vocacional no ensino superior: Satisfação com a formação e desempenho acadêmico. Revista Brasileira de Orientação Profissional São Paulo, v. 12, n. 1, p. 15-27, jan-jun. 2011.

OLIVEIRA, Marina Cardoso de; DELA COLETA, Marília Ferreira. Adaptação e validação da Escala Combinada de Atitudes da Maturidade de Carreira (CDA): Versão para estudantes universitários. Revista Brasileira de Orientação Profissional, São Paulo, v.9, n.2, p. 45-65. 2008.

OLIVEIRA, Marina Cardoso de; GUIMARÃES, Vanessa da Fonseca.; DELA COLETA, Marília Ferreira. Modelo Desenvolvimentista de Avaliação e Orientação de Carreira proposto por Donald Super. Revista Brasileira de Orientação Profissional, São Paulo, v.7, n.2, p. 11-18. 2006. 
OLIVEIRA, Marina Cardoso de; MELO-SILVA, Lucy Leal; COLETA, Marília Ferreira Dela. Pressupostos teóricos de super: datados ou aplicáveis à psicologia vocacional contemporânea? Revista Brasileira de Orientação Profissional, São Paulo, v. 13, n. 2, p. 223-234, dez. 2012.

PINTO, Telma Maranhão Gomes; CASTANHO, Marisa Irene Siqueira. Sentidos da escolha e da orientação profissional: um estudo com universitários. Estudos de Psicologia, Campinas, v. 29, n. 3, p. 395-413, set. 2012 .

POLYDORO, Soely Aparecida Jorge; GUERREIRO-CASANOVA, Daniela C.. Escala de Autoeficácia na formação superior: construção e estudo de validação. Avaliação Psicológica, Porto Alegre, v.9, n.2, p. 267-278, ago. 2010.

SAMPAIO, Breno et. al. . Desempenho no vestibular, background familiar e evasão: evidências da UFPE. Economia Aplicada, Ribeirão Preto, v. 15, n. 2, p. 287-309, jun. 2011.

SARRIERA, Jorge Castellá et. al. Estudo comparativo da integração ao contexto universitário entre estudantes de diferentes instituições. Revista Brasileira de Orientação Profissional, v. 13, n. 2, p. 163-172, 2012.

SCHLEICH, Ana Lucia Righi; POLYDORO, Soely Aparecida Jorge; SANTOS, Acacia Aparecida Angeli dos. Escala de satisfação com a experiência acadêmica de estudantes do ensino superior. Avaliação Psicológica, Porto Alegre, v.5, n.1, p. 11-20. 2006.

SILVA, Cláudia Sampaio Corrêa da; COELHO, Paola Braga Meyer; TEIXEIRA, Marco Antônio Pereira. Relações entre experiências de estágio e indicadores de desenvolvimento de carreira em universitários. Revista Brasileira Orientacão Profissional, São Paulo, v. 14, n. 1, p.35-46, jun. 2013.

SOARES, Dulce Helena Penna. LIOP: Uma história de carreiras. Extensio: R. Eletr. de Extensão, Edição Especial 50 anos UFSC, p. 136-151, 2010.

SOARES, Dulce Helena Penna. A escolha profissional do jovem ao adulto. São Paulo: Summus, 2002. 196 p.

SPARTA, Mônica; BARDAGI, Marucia Patta; ANDRADE, Ana Maria Jung de. Exploração vocacional e informação profissional percebida em estudantes carentes. Aletheia, n.22, p. 79-88, jul/dez. 2005.

SPARTA, Mônica; BARDAGI, Marucia Patta; TEIXEIRA, Marco Antônio P.. Modelos e instrumentos de avaliação em orientação profissional: perspectiva histórica e situação no Brasil. Revista Brasileira de Orientação Profissional, São Paulo, v.7, n.2, p. 19-32. 2006.

TEIXEIRA, Marco Antônio Pereira. A experiência de transição entre a universidade e o mercado de trabalho na adultez jovem. 2002. 168 f.. Tese (Doutorado em Psicologia) Programa de Pós-Graduação em Psicologia do Desenvolvimento, Universidade Federal do Rio Grande do Sul. Porto Alegre, RS.

TEIXEIRA, Maria Odília. A abordagem sócio-cognitiva no aconselhamento vocacional: Uma reflexão sobre a evolução dos conceitos e da prática da orientação. Revista Brasileira de Orientação Profissional, São Paulo, v.9, n.2, p. 9-16. 2008. 
TEIXEIRA, Marco Antônio Pereira; BARDAGI, Marucia Patta; HUTZ, Cláudio Simon. Escalas de Exploração Vocacional (EEV) para universitários. Psicologia em Estudo, Maringá, v.12, n.1, p. 195-202, abr. 2007.

TEIXEIRA, Marco Antônio Pereira; DIAS, Ana Cristina Garcia. Escalas de exploração vocacional para estudantes de ensino médio. Estudos de Psicologia, Campinas, v.28, n.1, p. 8996, mar. 2011.

TEIXEIRA, Marco Antônio Pereira et. al.. Adaptação à universidade em jovens calouros. Psicologia escolar e educacional, v. 12, n. 1, p. 185-202, 2008. 